\title{
EFEITO DA CONCENTRAÇÃO DE ENZIMA E RAZÃO MOLAR DE SUBSTRATOS NA ACETILAÇÃO ENZIMÁTICA DE ÓLEO ESSENCIAL DE CRAVO-DA-ÍNDIA (Syzygium aromaticum L.)
}

\author{
G. N. PEREIRA ${ }^{1}$, R. A. $\operatorname{LOSS}^{1}$, M. J. A. $\operatorname{SILVA}^{1}$, D. A. LAROQUE ${ }^{1}$, L. A. $\operatorname{LERIN}^{1}$, D. \\ OLIVEIRA $^{1}$, J. V. OLIVEIRA ${ }^{1}$, J. L. NINOW ${ }^{1}$, H. HENSE $^{1}$ \\ ${ }^{1}$ Universidade Federal de Santa Catarina, Departamento de Engenharia Química e \\ Engenharia de Alimentos \\ E-mail para contato: denise_laroque@hotmail.com
}

\begin{abstract}
RESUMO - O óleo de cravo-da-Índia é um líquido amarelo claro, oleoso, imiscível em água, obtido pela destilação das flores, caules e folhas da árvore Syzygium aromaticum L. Vem sendo utilizado mundialmente como agente flavorizante nos alimentos, e como agente antimicrobiano, onde as propriedades biológicas são atribuídas a seu composto majoritário Eugenol. Processos enzimáticos têm sido apontados como uma alternativa sustentável para produção de compostos de valor para as indústrias farmacêutica, cosméticos e de alimentos. Desta forma, o presente trabalho objetivou avaliar o efeito da concentração de enzima e da razão molar de eugenol e anidrido acético na produção de acetato de eugenila via acetilação catalisada por Lipozyme TL IM. As concentrações de enzimas avaliadas foram 1,5 e $10 \%$ ( $\mathrm{m} / \mathrm{m}$ de substrato) e as razões molares foram 1:1, 1:5, 1:9 e 1:12, em intervalos de tempo variando de 15 a 360 minutos. Através do estudo cinético foi possível observar que as concentrações de enzima de 5 e 10\% favoreceram a obtenção de elevadas conversões em acetato de eugenila. Em relação à razão molar, somente a razão de 1:1 não favoreceu elevadas conversão em éster. Desta forma, foram definidas a concentração de enzima de $5 \%$ e razão molar de eugenol e anidrido acético de 1:5 como as condições otimizadas para a produção de acetato de eugenila.
\end{abstract}

\section{INTRODUÇÃO}

Desde tempos antigos as civilizações focaram na atividade antimicrobiana presente nas essências de óleos de várias plantas que apresentam componentes benéficos e terapêuticos nos campos da medicina. Neste sentido, óleos essenciais derivados de plantas aromáticas medicinais têm excepcionalmente bons efeitos antimicrobianos, antimicóticos e antitoxigênicos, contra bactérias, leveduras, fungos filamentosos e vírus (Devi et al., 2010), fato que faz com que estes compostos tenham recebido grande atenção na aplicação em alimentos como aditivos antimicrobianos, por suas propriedades hidrofóbicas que limitam sua dispersão ajudando à estabilização em sistemas aquosos dentro dos alimentos (Brenes; Roura, 2010). 
Especiarias como cravo-da-índia, orégano (Origanum vulgare), menta (Mentha piperita), tomilho (Thymus vulgaris) e canela (Cinnamomum zeylanicum) têm sido utilizadas como conservantes de alimentos há vários anos. O cravo-da-índia em particular atraiu mais atenção uma vez que apresentou maior potencial antioxidante e antimicrobiano destacando-se entre as especiarias (Shan et al., 2005). O óleo essencial de cravo-da-índia é um efetivo agente antimicrobiano e antioxidante, sendo estas características atribuídas ao seu composto majoritário, o eugenol (Ayoola et al., 2008). Porém, a aplicação direta deste composto fenólico volátil apresenta algumas desvantagens, principalmente por apresentar baixa estabilidade devido ao radical hidroxila presente na sua molécula que é particularmente instável na presença de fatores como luz, ar, umidade e altas temperaturas. Uma alternativa seria a substituição desse radical através da proteção de grupos, sendo que, além de apresentar muitas vantagens em relação às propriedades biológicas, surge a possibilidade de que seus derivados sejam acilados, esterificados, acetilados, entre outros, apresentem melhores propriedades (Karmakar et al., 2012; Huang et al., 2002; Carrasco et al., 2008).

Desta forma, modificações moleculares, como a proteção de grupos funcionais da estrutura da molécula do eugenol, através de reações de acetilação, surgem como uma alternativa para minimizar os problemas de estabilidade. Processos que incluem catálise química são altamente questionados em relação à contaminação não somente do produto como também dos resíduos altamente tóxicos gerados no processo. O uso de reações catalisadas por enzimas contornam muitos problemas, devido à especificidade do substrato, régio e enantiosseletividade destes biocatalisadores, que podem ser utilizados em condições reacionais brandas. Outra vantagem interessante da modificação enzimática, do ponto de vista comercial, é que realizada em sistema livre de solvente, forma-se um composto catalogado como natural com valor agregado, sem gerar resíduos tóxicos ao ambiente facilitando etapas, como a de purificação, diminuindo o custo operacional. Desta forma, biocatalisadores enzimáticos são uma alternativa sustentável, promissora e efetiva para produção de compostos específicos ou complexos requeridos pelas indústrias.. Dentro deste contexto, este trabalho objetiva a produção de acetato de eugenila através de reação de acetilação enzimática em sistema livre de solvente, usando como substrato eugenol, presente no óleo essencial de cravo-da-índia e anidrido acético, avaliando o efeito de diferentes concentrações de enzima e de razões molares (eugenol:anidrido acético).

\section{METODOLOGIA}

\subsection{Enzima}

Lipozyme TL IM - lipase produzida por fermentação submersa de Thermomyces lanuginosus e imobilizada em resina fenólica e adequada para aplicação em reatores de leito fixo, pelo fato de ser granulada (Novozymes Brasil/ Araucária - PR). Esta apresenta especificidades nas posições 1,3 do triglicerídeo. É recomendável o uso em solventes orgânicos, uma vez que em meio aquoso, o suporte pode sofrer solvatação. Atividade catalítica: 75 IUN.g ${ }^{-1}$; densidade 0,42 g.mL ${ }^{-1}$; diâmetro de partícula: 0,3 - 1,0 mm; conteúdo de água: $5 \%$. 


\subsection{Reagentes}

Como substrato foram utilizados óleo essencial de folha de cravo-da-índia (Eugenia caryophyllus) adquirido da Ferquima Comércio de Óleos Essenciais Ltda e anidrido acético $\left(\mathrm{Ac}_{2} \mathrm{O}\right.$ ) ou $\mathrm{C}_{4} \mathrm{H}_{6} \mathrm{O}_{3}$ (Sigma-Aldrich). Hexano $\mathrm{C}_{6} \mathrm{H}_{14}$ (Sigma-Aldrich) foi utilizado para lavagem da enzima após a reação. Para as análises cromatográficas foi utilizado o padrão de acetato de eugenila $\mathrm{C}_{12} \mathrm{H}_{14} \mathrm{O}_{3}$ (Sigma-Aldrich). Para o preparo das soluções foi utilizado como solvente Diclorometano - $\mathrm{CH}_{2} \mathrm{Cl}_{2}$ (Sigma-Aldrich).

\subsection{Aparato experimental para a síntese enzimática de acetato de eugenila em sistema livre de solvente}

Os ensaios para sintetizar acetato de eugenila foram realizados em mistura reacional contendo óleo essencial de folha de cravo-da-Índia como fonte de eugenol e anidrido acético. Após dissolução completa dos substratos, a enzima foi adicionada, sendo o tempo reacional contado a partir da adição da mesma. Todos os ensaios realizados foram conduzidos a $70{ }^{\circ} \mathrm{C} \mathrm{e}$ realizados em banho termostatizado com agitação orbital $(250 \mathrm{rpm})$. Após o término do tempo de reação, o biocatalisador foi filtrado com papel filtro e solvente orgânico para uma maior remoção do acetato de eugenila aderido ao suporte da enzima e nas paredes dos frascos. As amostras foram evaporadas sob vácuo por $10 \mathrm{~min}$ a $40^{\circ} \mathrm{C}$. A quantificação dos ésteres de acetato de eugenila foi realizada por cromatografia gasosa em equipamento Shimadzu GC2010 equipado com processador de dados, medindo-se a partir da redução do pico de eugenol.

\subsection{Estudo cinético da produção enzimática de acetato de eugenila}

Os efeitos da razão molar (RM) e da concentração da enzima [E] na cinética da reação foram avaliados para cada sistema reacional. Os tempos avaliados foram 15, 30, 45, 60, 120, 180, 240, 300, 360 minutos. As razões molares e concentrações da enzima [E] $(\% \mathrm{~m} / \mathrm{m}$ substratos) utilizadas no estudo são apresentadas nas Tabelas 1 e 2, respectivamente.

Tabela 1 - Efeito da concentração de enzima na produção enzimática de acetato de eugenila

\begin{tabular}{ccc}
\hline $\begin{array}{c}\text { Temperatura } \\
\left({ }^{\circ} \mathrm{C}\right)\end{array}$ & $\begin{array}{c}\text { Razão molar } \\
(\mathrm{mol} / \mathrm{mol})^{\mathrm{a}}\end{array}$ & $\begin{array}{c}{[\mathrm{E}]} \\
(\% \mathrm{~m} / \mathrm{m})\end{array}$ \\
\hline 70 & $1: 9$ & $1,5,10$ \\
\hline
\end{tabular}

aeugenol: anidrido acético

Tabela 2 - Efeito da razão molar na produção enzimática de acetato de eugenila

\begin{tabular}{ccc}
\hline $\begin{array}{c}\text { Temperatura } \\
\left({ }^{\circ} \mathrm{C}\right)\end{array}$ & $\begin{array}{c}\text { Razão molar } \\
(\mathrm{mol} / \mathrm{mol})^{\mathrm{a}}\end{array}$ & $\begin{array}{c}{[\mathrm{E}]} \\
(\% \mathrm{~m} / \mathrm{m})\end{array}$ \\
\hline 70 & $1: 1 ; 1: 5 ; 1: 9 ; 1: 12$ & 5 \\
\hline
\end{tabular}

aeugenol:anidrido acético 


\section{RESULTADOS E DISCUSSÃO}

Após otimizar as condições experimentais das variáveis estudadas na produção de acetato de eugenila, os efeitos da concentração de enzima [E] e da razão molar (RM) na cinética da reação de acetilação em sistema livre de solvente foram avaliados, a fim de definir um tempo reacional ideal.

A Figura 1 mostra o efeito da concentração de enzima Lipozyme TL IM (1, 5 e $10 \%$ $\mathrm{m} / \mathrm{m}$ de substrato) na cinética de produção enzimática de acetato de eugenila.

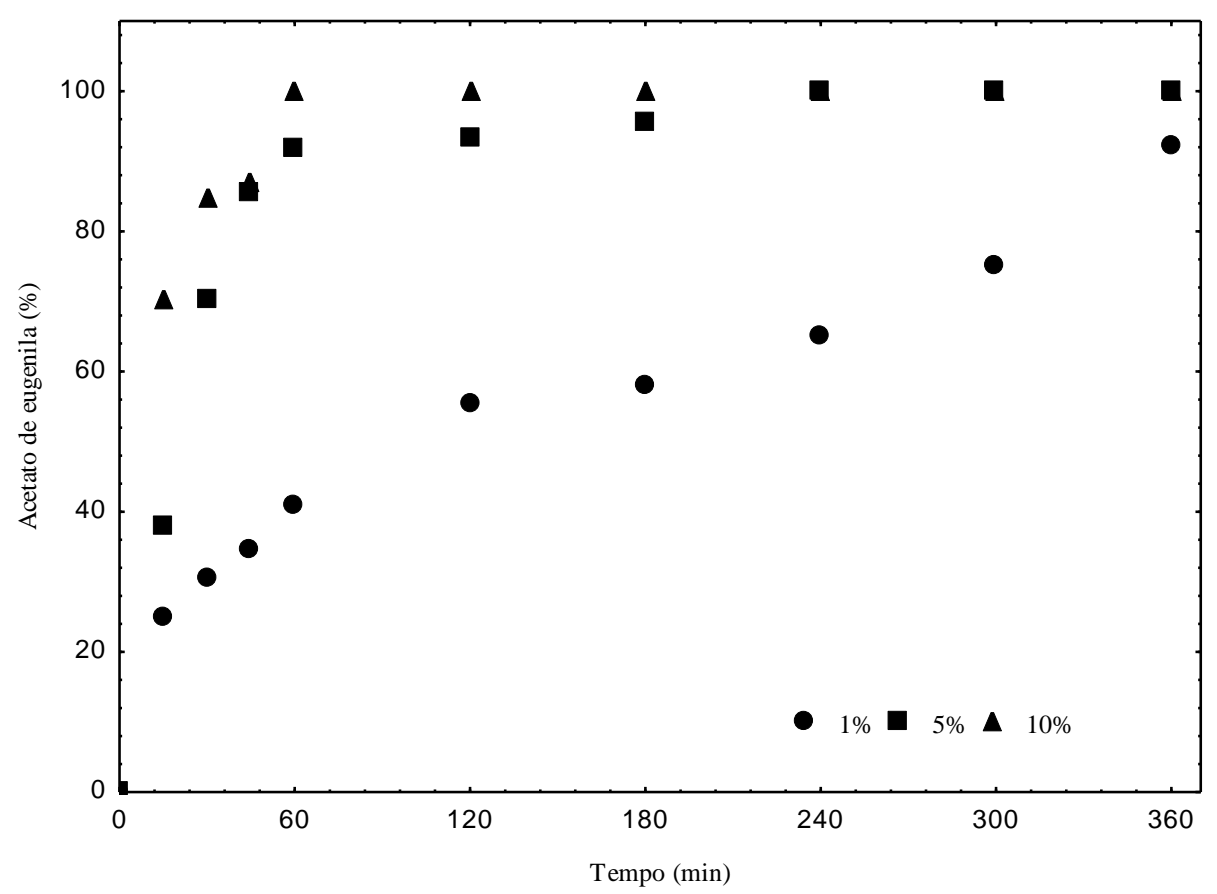

Figura 1 - Efeito da concentração de enzima Lipozyme TL IM na produção de acetato de eugenila à temperatura $70^{\circ} \mathrm{C}$, razão molar eugenol:anidrido acético 1:5 e velocidade de agitação $150 \mathrm{rpm}$

A partir da Figura 1 pode-se observar que com $1 \%$ de concentração de enzima atingiuse a máxima conversão em acetato de eugenila (76,3\%) em 360 min, sendo notavelmente diferente ao conseguido com 5 e $10 \%$ de enzima. Quando a enzima foi utilizada em concentração de 5\%, uma conversão de $90,7 \%$ foi obtida em $60 \mathrm{~min}$, sendo que após este tempo de reação não houve variação significativa de conversão, alcançando valores máximos de $96,9 \%$ em 360 min (6 h). Para a concentração de enzima de 10\%, conversão de 92,8\% foi obtida em 45 min, sendo que a máxima conversão de 100\% obtida após 240 min de reação. Considera-se baixa a diferença entre as conversões produzidas com as concentrações de 5 e $10 \%$ de enzima, optou-se por considerar a concentração de 5\% com 60 min $(1 \mathrm{~h})$ de tempo reacional como a melhor condição para a produção de acetato de eugenila catalisada pela Lipozyme TL IM, uma vez que nesta condição se reduz os custos de produção, devido ao fato que com menor quantidade de biocatalisador é possível obter conversões tão elevadas quanto as conversões obtidas em concentrações mais elevadas de enzima. Além disso, um excesso de enzima pode propiciar a formação de aglomerados, tornando o sítio ativo da enzima 
indisponível para os substratos no meio reacional, o que pode contribuir para uma diminuição da conversão da reação (Karra-Châabouni et al., 2006).

Babicz et al. (2010) avaliaram o efeito da concentração de enzima (1 e $2 \% \mathrm{~m} / \mathrm{m})$ na hidrólise de óleo de soja e observaram que quando utilizado $1 \%(\mathrm{~m} / \mathrm{m})$ de Lipozyme TL IM em $1,5 \mathrm{~h}$, o rendimento foi de $40 \%$, no entanto quando utilizado $2 \%(\mathrm{~m} / \mathrm{m})$ da mesma enzima, o rendimento foi de $32 \%$, em $3 \mathrm{~h}$.

Os efeitos das razões molares (1:1, 1:5, 1:9 e 1:12 eugenol:anidrido acético) nas cinéticas de produção enzimática de acetato de eugenila e nas velocidades específicas de consumo de substrato estão representados na Figura 2.

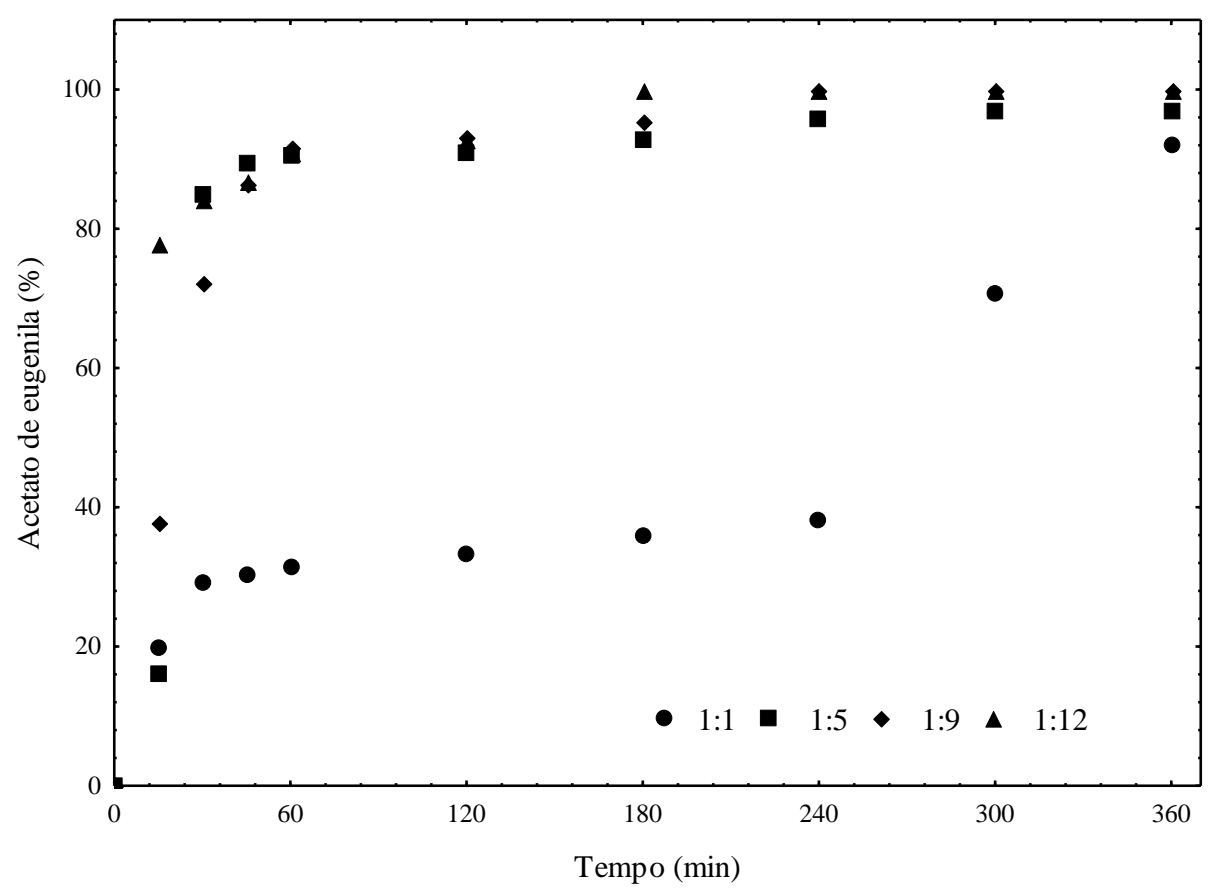

Figura 2 - Efeito da razão molar (eugenol:anidrido acético) na produção de acetato de eugenila à temperatura $70{ }^{\circ} \mathrm{C}$, concentração de enzima $5 \%$ e velocidade de agitação $150 \mathrm{rpm}$

A partir da Figura 2 pode-se observar que as conversões obtidas usando razão molar de 1:1 de substrato são baixas ao longo dos 360 min. Nas razões molares 1:5; 1:9 e 1:12, foram alcançadas conversões $>90 \%$ em 60 min. Desta forma, levando-se em consideração que um excesso de anidrido acético na reação leva a um maior tempo de purificação do éster de acetato de eugenila, e gera um maior custo de reagente, tendo conversões similares se escolheu como a melhor condição à razão molar de eugenol:anidrido acético de 1:5 em 120 $\min (2 \mathrm{~h})$ de tempo reacional, já que atingiu $92,9 \%$ de acetato de eugenila.

\section{CONCLUSÃO}

Neste trabalho foi avaliada a viabilidade técnica da esterificação do óleo essencial de cravo-da-índia para a síntese de acetato de eugenila via acetilação enzimática, em sistema livre de solvente. A partir das cinéticas foi possível obter as condições otimizadas para a produção de acetato de eugenila, sendo estas: razão molar de eugenol: anidrido acético de 1:5, 
concentração de enzima de $5 \%$ (m/m de substratos), com temperatura de $70{ }^{\circ} \mathrm{C}$, velocidade de agitação de $150 \mathrm{rpm}$ e tempo reacional de $2 \mathrm{~h}$. Sendo possível a utilização de menor quantidade de substratos em reações na ausência de solvente, tornando esse catalisador ambientalmente correto e com potencial para aplicação em processos industriais.

\section{REFERÊNCIAS}

AYOOLA, G.A.; LAWORE, F.M.; ADELOWOTAN, T.; AIBINU, I.E.; ADENIPEKUN, E.; COKER, H.A.B.; ODUGBEMI, T.O. Chemical analysis and antimicrobial activity of the essential oil of Syzigium aromaticum (clove). Afr. J. Microbiol. Res., v.2, p.162$166,2008$.

BABICZ, I.; LEITE, S.G.F.; DE SOUZA, R.O.M.A.; ANTUNES, O.A.C. Lipase-catalyzed diacylglycerol production under sonochemical irradiation. Ultrasonics Sonochem., v. 17 , p. 4-6, 2010.

BRENES, A.; ROURA, E. Essential oils in poultry nutrition: main effects and modes of action. Anim. Feed Sci. Technol., v.158, p.1-14, 2010.

CARRASCO, H.A.; ESPINOZA, L.C.; CARDILE, V.; GALLARDO, C.; CARDONA, W.; LOMBARDO, L.; CATALÁN, K.M.; CUELLAR, M.F.; RUSSOD, A. Eugenol and its synthetic analogues inhibit cell growth of human cancer cells (Part I). J. Braz. Chem. Soc., v.19, p.543-548, 2008.

DEVI, K.P.; NISHA, S.A.; SAKTHIVEL, S.; PANDIAN, S.K. Eugenol (an essential oil of clove) acts as an antibacterial agent against Salmonella typhi by disrupting the cellular membrane. J. Ethnopharmacol., v.130, p.107-115, 2010.

HUANG, H.; HO, S.H.; LEE, H.C.; YAP, Y.L. Insecticidal properties of eugenol, isoeugenol and methyleugenol and their effects on nutrition of Sitophilus zeamais Motsch. (Coleoptera: Curculionidae) and Tribolium castaneum (Herbst) (Coleoptera: Tenebrionidae). J. Stored Prod. Res., v.38, p.403-412, 2002.

KARMAKAR, S.; CHOUDHURY, M.; DAS, A.S.; MAITI, A.; MAJUMDAR, S.; MITRA, C. Clove (Syzygium aromaticum Linn) extract rich in eugenol and eugenol derivatives shows bone-preserving efficacy. Nat. Prod. Res., v.26, p.500-509, 2012.

KARRA-CHÂABOUNI, M.; GHAMGHI, H.; BEZZINE, S.; REKIK, A.; GARGOURI, Y. Production of flavour esters by immobilized Sthaphylococcus simulans lipase in a solvent-free system. Process Biochem., v.41, p.1692-1698, 2006.

SHAN, B.; CAI, Y.Z.; SUN, M.; CORK, H. Antioxidant capacity of 26 spice extracts and characterization of their phenolic constituents. J. Agr. Food Chem., v.53, p.7749-7759, 2005 . 